\title{
(6) OPEN ACCESS \\ Effect of ski geometry and standing height on kinetic energy: equipment designed to reduce risk of severe traumatic injuries in alpine downhill ski racing
}

\author{
Matthias Gilgien, ${ }^{1}$ Jörg Spörri, ${ }^{2}$ Josef Kröll, ${ }^{2}$ Erich Müller ${ }^{2}$
}

\begin{abstract}
- Additional material is published online only. To view please visit the journal online (http://dx.doi.org/10.1136/ bjsports-2015-095465).

${ }^{1}$ Department of Physical Performance, Norwegian School of Sport Sciences, Oslo Norway

${ }^{2}$ Department of Sport Science and Kinesiology, University of Salzburg, Hallein-Rif, Austria
\end{abstract}

\section{Correspondence to} Matthias Gilgien, Department of Physical Performance, Norwegian School of Sport Sciences, Sognsveien 220, Oslo 0806, Norway: matthias.gilgien@nih.no

Accepted 3 November 2015

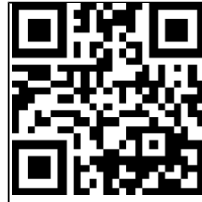

Open Access can to access more free content

\section{CrossMark}

To cite: Gilgien M, Spörri J, Kröll J, et al. Br J Sports Med 2016;50:8-13.

\section{ABSTRACT}

Background Injuries in downhill (DH) are often related to high speed and, therefore, to high energy and forces which are involved in injury situations. Yet to date, no study has investigated the effect of ski geometry and standing height on kinetic energy $\left(\mathrm{E}_{\mathrm{KIN}}\right)$ in $\mathrm{DH}$. This knowledge would be essential to define appropriate equipment rules that have the potential to protect the athletes' health.

Methods During a field experiment on an official World Cup DH course, 2 recently retired world class skiers skied on 5 different pairs of skis varying in width, length and standing height. Course characteristics, terrain and the skiers' centre of mass position were captured by a differential Global Navigational Satellite System-based methodology. $E_{K I N}$, speed, ski-snow friction force $\left(F_{F}\right)$, ground reaction force $\left(F_{G R F}\right)$ and skisnow friction coefficient $\left(\right.$ Coeff $\left._{F}\right)$ were calculated and analysed in dependency of the used skis.

Results In the steep terrain, longer skis with reduced width and standing height significantly decreased average $E_{\text {KIN }}$ by $3 \%$. Locally, even larger reductions of $E_{\text {KIN }}$ were observed (up to 7\%). These local decreases in $E_{\text {KIN }}$ were mainly explainable by higher $F_{F}$. Moreover, Coeff $_{F}$ differences seem of greater importance for explaining local $F_{F}$ differences than the differences in $\mathrm{F}_{\text {GRF. }}$.

Conclusions Knowing that increased speed and $E_{\text {KIN }}$ likely lead to increased forces in fall/crash situations, the observed equipment-induced reduction in $E_{\text {KIN }}$ can be considered a reasonable measure to improve athlete safety, even though the achieved preventative gains are rather small and limited to steep terrain.

\section{INTRODUCTION}

Alpine ski racing is known to be a sport with a high risk of sustaining severe injuries. ${ }^{1} 2$ Injury rates for World Cup (WC) athletes were found to differ among the competition disciplines, particularly when calculated as injuries per 1000 runs: they increased from slalom to giant slalom, super-G and downhill (DH) with the knee as the most frequently injured body part. ${ }^{1}$ However, if injury risk is normalised with risk exposure time and calculated as the number of injuries per time skiing, the disciplines giant slalom, super-G and $\mathrm{DH}$ can be considered to be equally dangerous but for different reasons. ${ }^{3}$

With respect to the injury causes, a recent study assessing the skier biomechanics in WC alpine skiing found that injuries in super-G and $\mathrm{DH}$ are most likely due to high speeds, jumps and higher workloads caused by long competition times. ${ }^{3}$
High speed is expected to shorten the preparation time necessary for the skier to adapt to jumps and demanding course sections. ${ }^{3}$ High speed is also expected to increase jump length and air time, resulting in an increased risk of falling. ${ }^{3}{ }^{4}$ Furthermore, high speed and, therefore, high kinetic energy $\left(E_{\mathrm{KIN}}=1 / 2 \times\right.$ mass $\times$ speed $\left.^{2}\right)$ are likely to increase the forces that occur at the impact in fall or crash situations. ${ }^{3}$ Consequently, reducing $\mathrm{E}_{\mathrm{KIN}}$ can be considered a potential prevention tool, particularly in super-G and $\mathrm{DH}^{3}$

Thus far, it is known that course setting might be an effective preventative measure to control skier speed and $\mathrm{E}_{\mathrm{KIN}}$ in steep terrain in DH courses. ${ }^{5} 6$ In addition, equipment-related measures, namely different ski geometries and standing height (ie, distance from ski base to binding plate cover), might potentially reduce $\mathrm{E}_{\mathrm{KIN}} /$ speed, as was hypothesised by expert stakeholders of the WC ski racing community. ${ }^{7}$ Yet to date, scientific knowledge on DH is very limited, ${ }^{3-6}{ }^{8-10}$ and no field study has assessed equipment-related, preventative measures in super-G and DH.

Therefore, this study aimed to investigate the effect of modifications in ski geometry (ski length, ski width) and standing height of DH skis on speed and $\mathrm{E}_{\mathrm{KIN}}$ while skiing a WC DH course.

\section{METHODS}

Measurement protocol and data collection

Two recently retired (10 months) male WC athletes (age: $34.5 \pm 4.5$ years; height: $184 \pm 2 \mathrm{~cm}$; weight: $98.5 \pm 1.5 \mathrm{~kg}$ ) skied several runs on five different pairs of skis varying in width (W), standing height $(\mathrm{H})$ and length (L). For each skier, 4 runs per ski were considered for the data analysis (ie, a total of 40 runs). The test order of the skis was randomised and snow conditions were monitored. The reference ski $\left(\mathrm{SKI}_{\mathrm{REF}}\right)$ was built according to the International Ski Federation (FIS) equipment rules being valid until Winter Season 2011/2012. ${ }^{11}$ The specifications of all other skis were defined by an expert group consisting of representatives of the Ski Racing Suppliers Association (SRS), FIS Race Directors and researchers who took into consideration the existing scientific knowledge and practical experience (table 1). All prototypes were constructed by one company under the guidance of SRS, strictly adhered to the predefined geometrical variables (table 1) and material composition.

The biomechanical field experiment was conducted on the lower part of the FIS WC DH course in Åre (Sweden), directly after a women's WC DH race. The first section of the course was 
Table 1 Specification of the basic geometric parameters of the DH skis used for the experiments

\begin{tabular}{lccccc}
\hline & SKI $_{\text {REF }}{ }^{*}$ & SKI $_{\text {WH }}$ & SKI $_{\mathbf{L H}}$ & SKI $_{\text {WL }}$ & SKI $_{\text {WLH }}$ \\
\hline Width (mm) & 69 & 65 & 69 & 65 & 65 \\
Standing height (mm) & 50 & 40 & 40 & 50 & 40 \\
Length (cm) & 216 & 216 & 220 & 220 & 220 \\
\hline
\end{tabular}

${ }^{*} \mathrm{Ski}_{\mathrm{REF}}$ represents the original DH racing skis according to the FIS equipment rules valid until Winter Season 2011/2012. ${ }^{8}$

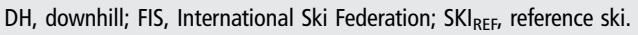

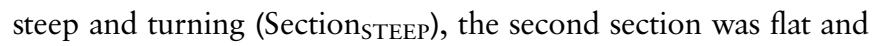
less turning (Section FLAT; figure 1). The analysis for Section $_{\text {STEEP }}$ started at the first gate where skiers reached $19.9 \mathrm{~m} / \mathrm{s}$ and ended at gate number 9. The analysis of Section FLAT $_{\text {started at gate } 11}$ and ended at gate 21 .

Course setting and the snow surface geomorphology were captured using static differential global navigation satellite systems (dGNSS) and were reconstructed in a digital terrain model (DTM), as conducted in earlier studies. ${ }^{5} 6$ Each skier's instantaneous three-dimensional position was captured by kinematic dGNSS $(50 \mathrm{~Hz})$, using GPS and the Russian (GLONASS) global navigation satellite systems, L1 and L2 signals, and was carried in a small backpack as described in detail in previous studies. ${ }^{12} 13$ The centre of mass (CoM) position of the skier was approximated using a virtual pendulum model, which was attached to the skier's antenna position and the intersection of the pendulum with the snow surface DTM. ${ }^{12}$

\section{Postprocessing and parameter calculations}

Course setting was characterised by gate distance and horizontal gate distance, ${ }^{14}{ }^{15}$ using the definition of double gate turns in speed disciplines introduced in earlier studies. ${ }^{5616}$ Skier speed, turn radius and $\mathrm{E}_{\mathrm{KIN}}$ were derived from the CoM position (measurement-system accuracy: $0.1 \mathrm{~m}) .{ }^{12}$ Ground reaction force

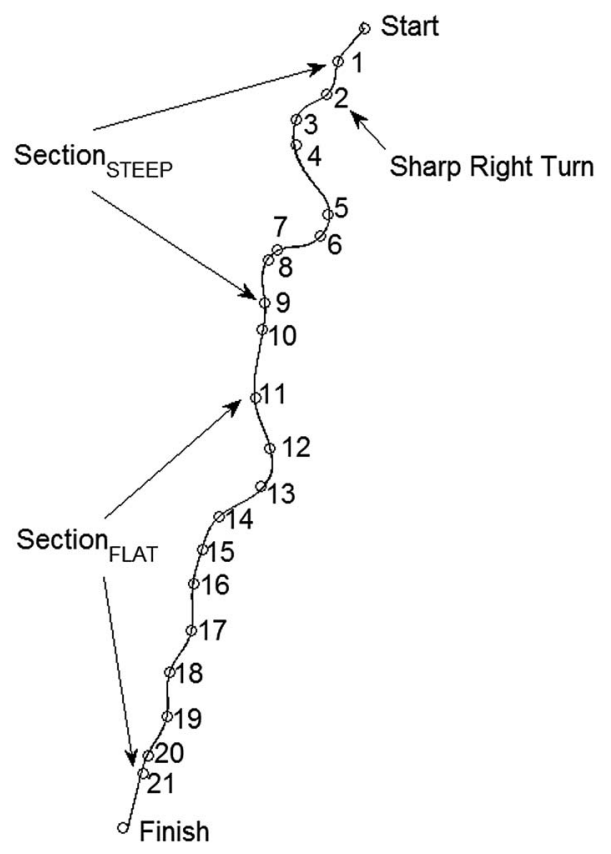

Figure 1 Map of the course with gates, gate numbers and skier trajectories. The boundaries of the steep section (Section STEEP $_{\text {) }}$ and the flat section $\left(\right.$ Section $\left._{\text {FLAT }}\right)$ and the sharp right turn at gate 2 are indicated with arrows.
Table 2 Characteristics of the course for the steep (Section STEEP) $_{\text {) }}$ and the flat (Section FLAT) sections of the downhill course

\begin{tabular}{lll}
\hline Parameter & Entire course & \\
\hline Course length $(\mathrm{m})$ & 1302 & \\
Vertical drop $(\mathrm{m})$ & 402 & \\
Number of gates () & 21 & \\
Mean run time $(\mathrm{s})$ & 50.0 & Section $_{\text {FLAT }}$ \\
\hline & Section $_{\text {STEEP }}$ & -15 \\
\hline Median terrain inclination $\left({ }^{\circ}\right)$ & -23 & 61.67 \\
Median gate distance $(\mathrm{m})$ & 84.23 & 12.23 \\
Median horizontal gate distance $(\mathrm{m})$ & 35.65 & 11 \\
Mean direction change from gate to gate $\left(^{\circ}\right)$ & 23 & \\
\hline
\end{tabular}

$\left(\mathrm{F}_{\mathrm{GRF}}\right)$ and ski-snow friction force $\left(\mathrm{F}_{\mathrm{F}}\right)$ were calculated by the application of a kinetic model on the CoM position, the virtual pendulum model and the body extension (measurement-system accuracy: $63 \mathrm{~N}$ for $\mathrm{F}_{\mathrm{GRF}} ; 42 \mathrm{~N}$ for $\left.\mathrm{F}_{\mathrm{F}}\right) .{ }^{17}$ The ski-snow friction coefficient $\left(\right.$ Coeff $_{\mathrm{F}}$ ) was calculated as the coefficient of $\mathrm{F}_{\mathrm{F}}$ and $\mathrm{F}_{\mathrm{GRF}}{ }^{16}$ To compare the time series data of speed, turn radius, $\mathrm{E}_{\mathrm{KIN}}, \mathrm{F}_{\mathrm{GRF}}, \mathrm{F}_{\mathrm{F}}$ and Coeff $\mathrm{F}_{\mathrm{F}}$, between runs, parameters were spatially normalised based on an alternative approach specifically dedicated to the characteristics of competitive alpine DH skiing (see online supplementary data).

\section{Statistical analysis}

The statistical analysis was conducted for skiers A and B and for

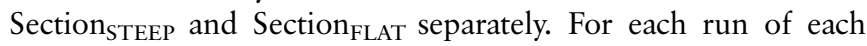
skier and each ski, $E_{\mathrm{KIN}}$ averages of the Section STEEP $_{\text {and }}$ Section $_{\text {FLAT }}$ were calculated. Based on these single $\mathrm{E}_{\mathrm{KIN}}$ section averages, participant mean $\pm S D$ values were computed for all tested skis. In addition, $\mathrm{E}_{\mathrm{KIN}}$ section averages were tested for significant differences between the tested skis using a one-way analysis of variance (ANOVA; $\mathrm{p}<0.05$ ). For pairwise comparison, the post hoc Tukey-Kramer correction was used. To assess if the response to the ski intervention was similar for both skiers, the average $\mathrm{E}_{\mathrm{KIN}}$ difference between $\mathrm{SKI}_{\mathrm{REF}}$ and each ski type was compared between the skiers for each section. To test whether these ski response differences between the skiers were statistically significant, two-sided Student t tests $(\mathrm{p}<0.05)$ were used.

Finally, a local subsection in which the equipment-induced effects on $\mathrm{E}_{\mathrm{KIN}}$ seemed to be the greatest was defined. Within this subsection (the sharp right turn at gate 2), the relation between $\mathrm{E}_{\mathrm{KIN}}$ and the $\mathrm{E}_{\mathrm{KIN}}$ explanatory parameters were investigated by the use of: (1) Spearman's rank correlation coefficients between the ${ }_{W L H} S K I_{W L H}-S K I_{\text {REF }}$ differences in speed and the ${ }_{\text {WLH }} \mathrm{SKI}_{\mathrm{WLH}}-\mathrm{SKI}_{\mathrm{REF}}$ differences in $\mathrm{F}_{\mathrm{F}}$; and (2) a multiple

Table 3 Characteristics of speed and kinetic energy $\left(E_{\text {KIN }}\right)$ for the course sections steep (Section STEEP $_{\text {) and flat (Section }}$ FLAT)

\begin{tabular}{lllll}
\hline Parameter & Section $_{\text {STEEP }}$ & \multicolumn{2}{l}{ Section $_{\text {FLAT }}$} \\
\hline Group mean of $\mathrm{E}_{\text {KIN }}(\mathrm{J} / \mathrm{BW})$ & 30.9 & & 44.7 & \\
Group mean of speed $(\mathrm{m} / \mathrm{s})$ & 24.6 & & 29.6 & \\
\hline & Skier A & Skier B & Skier A & Skier B \\
\hline E KIN $(\mathrm{J} / \mathrm{BW})^{\text {Speed }(\mathrm{m} / \mathrm{s})}$ & 31.1 & 30.6 & 45.3 & 41.1 \\
\hline
\end{tabular}




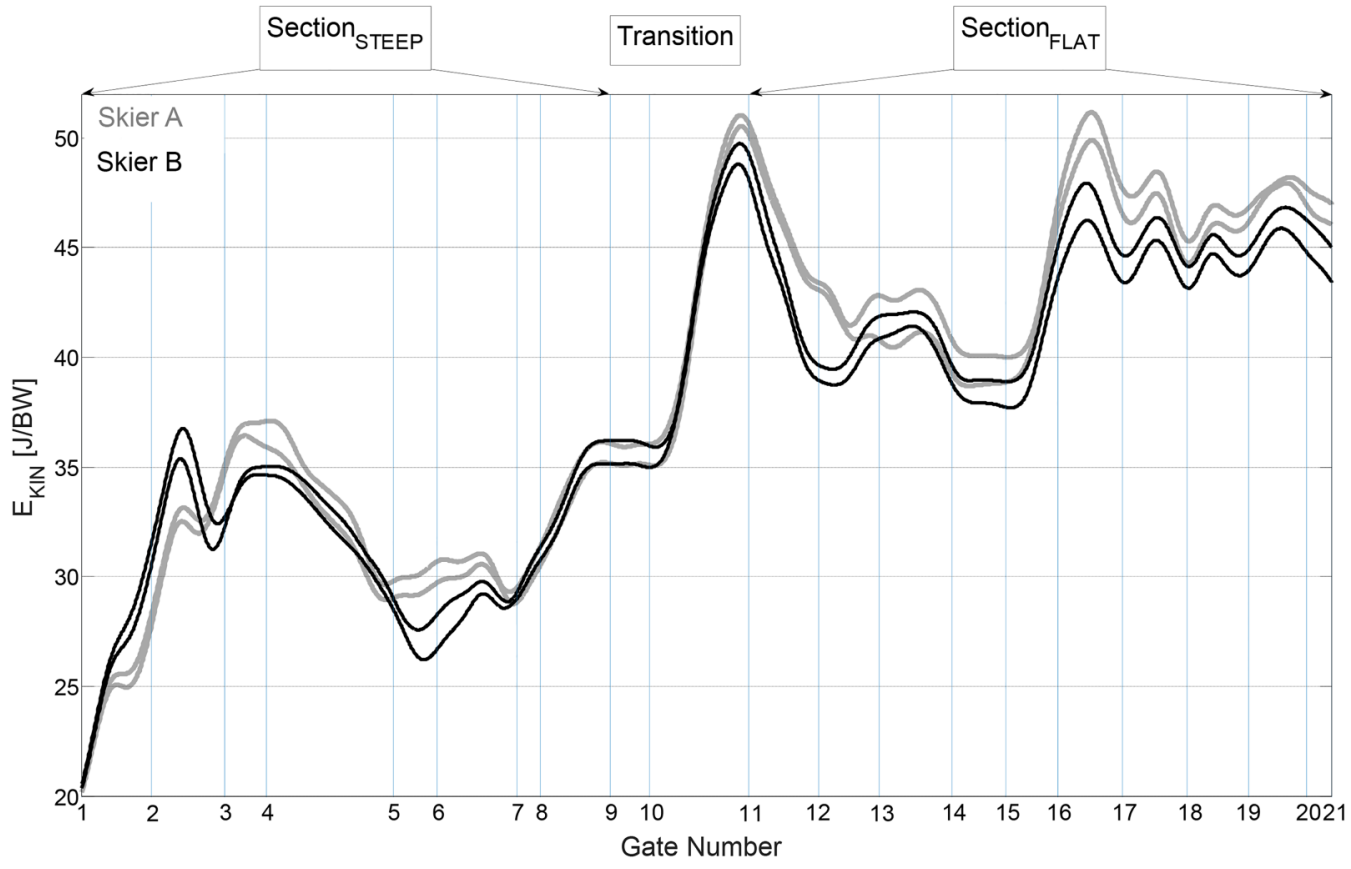

Figure 2 Areas around the estimate of the mean $( \pm S E)$ illustrating instantaneous kinetic energy $\left(E_{K I N}\right)$ for both skiers skiing on reference ski. Grey

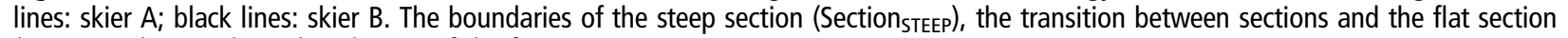
$\left(\right.$ Section $\left._{\text {FLAT }}\right)$ are indicated at the top of the figure.

regression analysis assessing the contribution of differences in Coeff $_{\mathrm{F}}$ and in $\mathrm{F}_{\mathrm{GRF}}$ to explain the local differences in $\mathrm{F}_{\mathrm{F}}$ between $\mathrm{SKI}_{\mathrm{REF}}$ and $\mathrm{SKI}_{\mathrm{WLH}}$.

\section{RESULTS}

\section{General characteristics of the test setup}

Table 2 presents the course characteristics of the test setup on the WC DH course. Table 3 shows the average speed and $\mathrm{E}_{\mathrm{KIN}}$ within Section STEEP $_{\text {and Section }}$ FLAT for both skiers. Figure 2 illustrates the instantaneous $\mathrm{E}_{\mathrm{KIN}}$ (ie, its mean $\pm \mathrm{SE}$ from start of

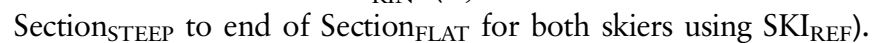
It can be visually observed that $\mathrm{E}_{\mathrm{KIN}} /$ speed was higher in

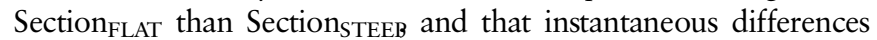
between the skiers were present at various locations of the course.

\section{Differences in $E_{\text {KIN }}$ between the tested skis within specific sections of the course}

The results reporting the $\mathrm{E}_{\mathrm{KIN}}$ section average differences between the tested skis are shown in table 4. The one-way
ANOVA analysis was significant for both skiers for Section

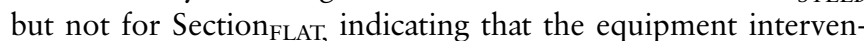
tion did not have an effect on $\mathrm{E}_{\mathrm{KIN}} /$ speed in Section FLAT $_{\text {. At the }}$ pairwise comparisons (right side of table 4), a difference is negative if the modified skis showed smaller $\mathrm{E}_{\mathrm{KIN}}$ mean values than $\mathrm{SKI}_{\mathrm{REF}}$ The only ski prototypes that caused a statistically significant reduction in $\mathrm{E}_{\mathrm{KIN}}$ /speed compared with $\mathrm{SKI}_{\mathrm{REF}}$ was $\mathrm{SKI}_{\mathrm{WLH}}$. This finding was independently observed for both

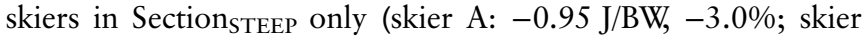
B: $-1.0 \mathrm{~J} / \mathrm{BW},-3.2 \%)$.

The extent to which a certain pair of skis caused the same $\mathrm{E}_{\mathrm{KIN}} /$ speed difference with respect to $\mathrm{SKI}_{\mathrm{REF}}$ was not significantly different between skiers but was significantly smaller in Section STEEP $_{\text {S }}$ $(0.07 \pm 0.03 \mathrm{~m} / \mathrm{s})$ than in Section $\mathrm{FLAT}(0.21 \pm 0.08 \mathrm{~m} / \mathrm{s})$.

\section{Differences in $\mathrm{E}_{\mathrm{KIN}}$ between $\mathrm{SKI}_{\mathrm{WLH}}$ and $\mathrm{SKI}_{\mathrm{REF}}$ in Section $_{\text {STEEP }}$}

Figure 3 illustrates the instantaneous differences in $\mathrm{E}_{\mathrm{KIN}}$ between $\mathrm{SKI}_{\mathrm{REF}}$ and SKI $\mathrm{WLH}$ for skiers $\mathrm{A}$ and $\mathrm{B}$ within

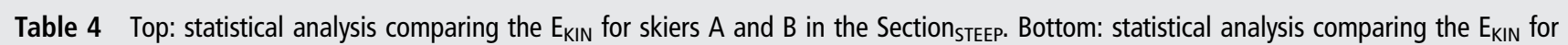
skiers $A$ and $B$ in the Section FLAT

\begin{tabular}{|c|c|c|c|c|c|c|c|c|c|c|}
\hline \multirow[b]{2}{*}{ Ski } & \multicolumn{5}{|l|}{$\mathrm{E}_{\mathrm{KIN}}(\mathrm{J} / \mathrm{BW})$} & \multirow{2}{*}{$\begin{array}{l}\text { ANOVA } \\
\text { p Value }\end{array}$} & \multicolumn{4}{|c|}{ Pairwise comparisons (\%) } \\
\hline & $S K I_{\text {REF }}$ & $S K I_{W H}$ & $\mathrm{SKI}_{\mathrm{LH}}$ & $\mathrm{SKI}_{\mathrm{WL}}$ & SKI $\mathrm{WLH}_{\mathrm{HL}}$ & & $S K I_{\mathrm{WH}}-\mathrm{SKI} I_{\mathrm{REF}}$ & $S K I_{\mathrm{LH}}-\mathrm{SKI} \mathrm{I}_{\mathrm{REF}}$ & $\mathrm{SKI}_{\mathrm{WL}}-\mathrm{SKI} \mathrm{R}_{\mathrm{REF}}$ & $\mathrm{SKI}_{\mathrm{WLH}}-\mathrm{SKI} \mathrm{I}_{\mathrm{REF}}$ \\
\hline \multicolumn{11}{|c|}{ Section $_{\text {STEEP }}$} \\
\hline Skier A & $31.35 \pm 0.30$ & $31.15 \pm 0.04$ & $31.44 \pm 0.24$ & $31.65 \pm 0.37$ & $30.40 \pm 0.43$ & $.001^{* * *}$ & & & & $-3.0^{*}$ \\
\hline Skier B & $31.08 \pm 0.18$ & $31.15 \pm 0.04$ & $31.05 \pm 0.25$ & $31.2 \pm 0.42$ & $30.08 \pm 0.55$ & $.005^{* * *}$ & & & & $-3.2^{*}$ \\
\hline \multicolumn{11}{|l|}{ Section $_{\text {FLAT }}$} \\
\hline Skier A & $45.24 \pm 0.47$ & $45.47 \pm 0.61$ & $45.67 \pm 1.01$ & $46.32 \pm 0.08$ & $45.10 \pm 0.64$ & 0.209 & & & & \\
\hline Skier B & $43.30 \pm 0.96$ & $45.07 \pm 0.61$ & $44.54 \pm 0.15$ & $44.96 \pm 1.30$ & $44.70 \pm 0.73$ & 0.108 & & & & \\
\hline
\end{tabular}




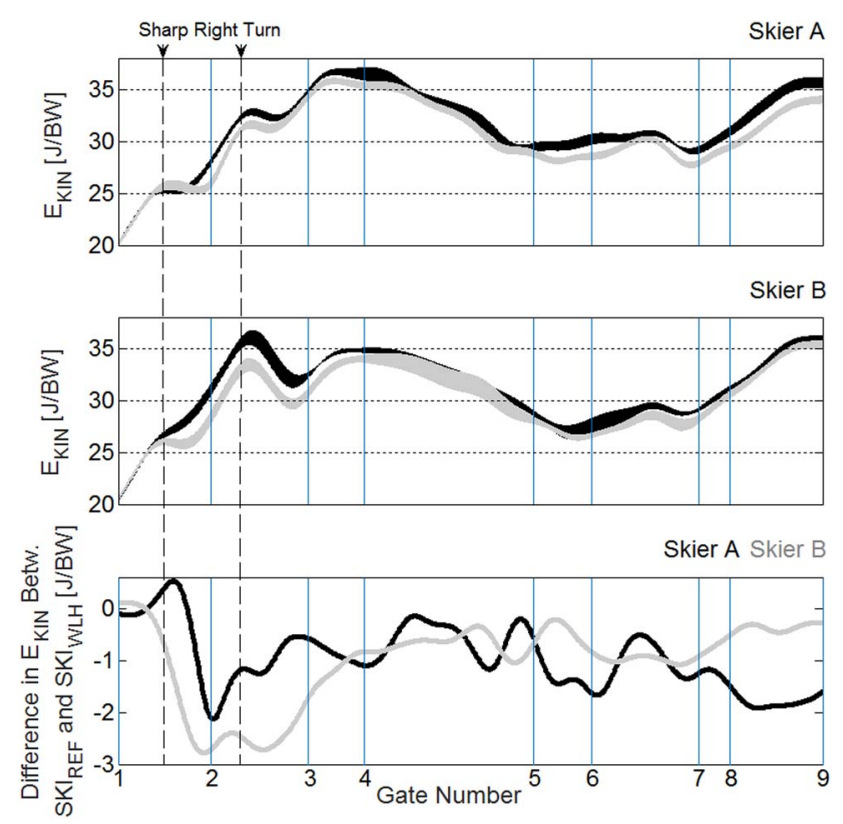

Figure 3 Top (skier A) and middle (skier B): areas of uncertainty around the estimate of the mean $( \pm \mathrm{SE})$ illustrating instantaneous kinetic energy $\left(\mathrm{E}_{\mathrm{KIN}}\right)$ and reference ski $\left(\mathrm{SKI}_{\mathrm{REF}}\right)$ versus SKI $\mathrm{WLH}_{\mathrm{WL}}$ within

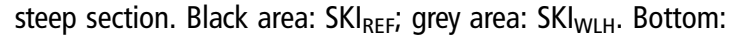
instantaneous differences between $\mathrm{SKI}_{\mathrm{REF}}$ and $\mathrm{SKI} \mathrm{I}_{\mathrm{WLH}}$ for skier $\mathrm{A}$ (black line) and for skier B (grey line). The dashed lines indicate the sharp right turn at gate 2 .

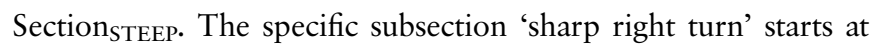
the first gate, where mean speed is equal for both skiers and skis (skier A: $19.9 \mathrm{~m} / \mathrm{s}$ with $\mathrm{SKI}_{\mathrm{REF}}$ and $19.9 \mathrm{~m} / \mathrm{s}$ with $\mathrm{SKI}_{\mathrm{WLH}}$; skier B: $20.0 \mathrm{~m} / \mathrm{s}$ with $\mathrm{SKI}_{\text {REF }}$ and $20.0 \mathrm{~m} / \mathrm{s}$ with $\mathrm{SKI}_{\mathrm{WLH}}$ ), and ends when the average turn radius of both skiers and skis exceeded $125 \mathrm{~m}$ after the passage of gate 2 . Within this subsection, the percentage differences in $\mathrm{E}_{\mathrm{KIN}}$ between $\mathrm{SKI}_{\mathrm{WLH}}$ and $\mathrm{SKI}_{\mathrm{REF}}$ were $-3.6 \%$ for skier $\mathrm{A}$ and $-7.0 \%$ for skier B.

Table 5 shows the Spearman's rank correlation coefficients describing the relation between the $\mathrm{SKI}_{\mathrm{WLH}}-\mathrm{SKI}_{\mathrm{REF}}$ differences in speed and the corresponding differences in $\mathrm{F}_{\mathrm{F}}$ during the sharp right turn in the steep section for skiers A and B. For skier $\mathrm{B}$, speed was significantly correlated with $\mathrm{F}_{\mathrm{F}}$

Table 6 shows the results of the multiple regression analysis assessing the contribution of the ${ }_{\mathrm{WLH}} \mathrm{SKI}_{\mathrm{WLH}}-\mathrm{SKI}_{\mathrm{REF}}$ differences in Coeff $f_{\mathrm{F}}$ and in $\mathrm{F}_{\mathrm{GRF}}$ to explain the ${ }_{\mathrm{WLH}} \mathrm{SKI}_{\mathrm{WLH}}-\mathrm{SKI}_{\mathrm{REF}}$ difference in $\mathrm{F}_{\mathrm{F}}$ during the exemplary sharp right turn. This analysis indicated that the differences in $\operatorname{Coeff}_{\mathrm{F}}$ were more important than those in $\mathrm{F}_{\mathrm{GRF}}$ to explain the differences in $\mathrm{F}_{\mathrm{F}}$ (figure 4).

Table 5 Spearman's rank correlation coefficients describing the relation between the $\mathrm{SKI}_{\mathrm{WLH}}-\mathrm{SKI}_{\mathrm{REF}}$ differences in speed, and the differences in $F_{F}$ during the sharp right turn at gate 2 for skiers $A$ and $B$

\begin{tabular}{ll}
\hline Skier $\mathrm{A}$ & Speed \\
$\mathrm{F}_{\mathrm{F}}$ & $0.800^{\text {n.s. }}$ \\
Skier $\mathrm{B}$ & Speed \\
$\mathrm{F}_{\mathrm{F}}$ & $1.000^{* *}$ \\
\hline Level of significance: ${ }^{\mathrm{n}}$ not significant at $\mathrm{p}<0.05,{ }^{*} \mathrm{p}<0.05,{ }^{* *} \mathrm{p}<0.01,{ }^{* * *} \mathrm{p}<0.001$. \\
$\mathrm{F}_{\mathrm{F},}$ ski-snow friction force; $\mathrm{SKI}_{\mathrm{REF}}$ reference ski.
\end{tabular}

\section{DISCUSSION}

The main findings of the study were that no difference between

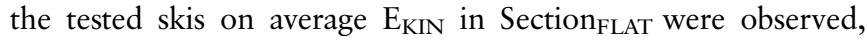
but $\mathrm{SKI}_{\mathrm{WLH}}$ caused a $\sim 3 \% \mathrm{E}_{\mathrm{KIN}}$ reduction for both skiers in Section $_{\text {STEEP }}$ compared with SKI $\mathrm{REF}_{\text {No }}$ other differences between $\mathrm{SKI}_{\mathrm{REF}}$ and the ski prototypes were observed. The largest reduction in $\mathrm{E}_{\mathrm{KIN}}$ was found in a sharp right turn at gate 2 for skier B $(-7.0 \%$ for skier B; $-3.6 \%$ for skier A). For skier $\mathrm{B}$, this reduction in $\mathrm{E}_{\mathrm{KIN}} /$ speed can be explained by increased $\mathrm{F}_{\mathrm{F}}$ which was mainly a result of increased Coeff $\mathrm{F}_{\mathrm{F}}$

\section{The progress of $\mathrm{E}_{\mathrm{KIN}}$ over the entire $\mathrm{DH}$ course}

The current study revealed that for both skiers $\mathrm{E}_{\mathrm{KIN}} /$ speed was lower in Section STEEP than in Section $_{\text {FLAT }}$ (table 3), which is in line with previous findings in men's WC alpine skiing. ${ }^{5} 618$ Moreover, based on the study findings presented in tables 2 and 3, speed, terrain and course setting can be considered representative for both female and male WC races. ${ }^{56}$

Comparing the individual progressions of $\mathrm{E}_{\mathrm{KIN}} / \mathrm{speed}$ between skiers A and B when skiing on $\mathrm{SKI}_{\mathrm{REF}}$, it seems that the general characteristics correspond well, but locally differ at certain spots along the course. A similar observation was already reported for other energy-related parameters in giant slalom by Supej. ${ }^{19}$ Additional analysis revealed that these interindividual differences in $\mathrm{E}_{\mathrm{KIN}}$ /speed on $\mathrm{SKI}_{\mathrm{REF}}$ were generally larger than the differences caused by the ski intervention. The agreement in response to the ski intervention between skiers was best in Section $_{\text {STEEP }}$ where the significant speed reductions were found between $S K I_{W L H}$ and $S K I_{\text {REF }}$ for both skiers. These two aspects might strengthen faith in the findings of this study.

\section{The effect of ski geometry and standing height on $\mathrm{E}_{\mathrm{KIN}}$}

Effects over the entire DH course

As shown in this study, none of the tested pairs of skis caused significant differences compared with $\mathrm{SKI}_{\mathrm{REF}}$ in Section FLAT. $_{\text {. }}$ However, a significant reduction of $\sim 3 \%$ in $\mathrm{E}_{\mathrm{KIN}}$ was found for the prototype with all three parameters altered $\left(\mathrm{SKI}_{\mathrm{WLH}}\right)$ in Section $_{\text {STEEP }}$ (table 4). Furthermore, postanalysis for Section $_{\text {STEEP }}$ revealed that the tested ski interventions had the smallest effect on $\mathrm{E}_{\mathrm{KIN}}$ /speed in the traverse (ie, between gates 4 and 5). Hence, the combination of steep terrain and turning courses seems to provoke differences between the modified skis and $\mathrm{SKI}_{\mathrm{REF}}$, while flat terrain in combination with 'gliding turns' (ie, turns, which can be skied in a tucked position) do not.

Table 6 Results of the multiple regression analysis assessing the contribution of differences in the average ski-snow friction coefficient $\left(\right.$ Coeff $\left._{\mathrm{F}}\right)$ and in the average ground reaction force $\left(\mathrm{F}_{\mathrm{GRF}}\right)$ to explain the difference in average ski-snow friction force $\left(\mathrm{F}_{\mathrm{F}}\right)$ between reference ski $\left(\mathrm{SKI}_{\mathrm{REF}}\right)$ and $\mathrm{SKI} \mathrm{WLH}_{\mathrm{WL}}$ during the sharp right turn at gate 2

\begin{tabular}{lcc}
\hline Predictors of $\mathrm{F}_{\mathrm{F}}$ & $\boldsymbol{\beta}$-weight & $\mathrm{p}$ Value \\
\hline Skier A & & \\
$\quad$ Coeff & & \\
$\quad \mathrm{F}_{\mathrm{GRF}}$ & 1.011 & 0.004 \\
Skier B & 0.123 & 0.011 \\
$\quad$ Coeff & & \\
$\mathrm{F}_{\mathrm{GRF}}$ & 0.944 & 0.006 \\
\hline Model for skier A: adjusted $\mathrm{R}^{2}=1.000 ; \mathrm{p}=0.012$. & 0.019 \\
\hline Model for skier B: adjusted $\mathrm{R}^{2}=1.000 ; \mathrm{p}=0.010$. &
\end{tabular}


Figure 4 Areas of uncertainty around the estimate of the mean $( \pm \mathrm{SE})$ illustrating speed, ski-snow friction force $\left(\mathrm{F}_{\mathrm{F}}\right)$, ground reaction force $\left(\mathrm{F}_{\mathrm{GRF}}\right)$ and ski-snow friction coefficient $\left(\right.$ Coeff $\left._{F}\right)$. Black area: reference ski; grey area: $\mathrm{SKI}_{\mathrm{WLH}}$. The in-depth analysis of speed and $\mathrm{F}_{\mathrm{F}}$ as well as $\mathrm{F}_{\mathrm{GRF}}$ and Coeff $_{F}$ for skier A (left side) and skier B (right side) are presented for the exemplary sharp right turn in steep section. G1 and G2 indicate gates 1 and 2, TS and TE indicate turn start (when mean turn radius across both ski types falls below $125 \mathrm{~m}$ ) and turn end (when mean turn radius across both ski types exceeds $125 \mathrm{~m}$ ).
Skier A
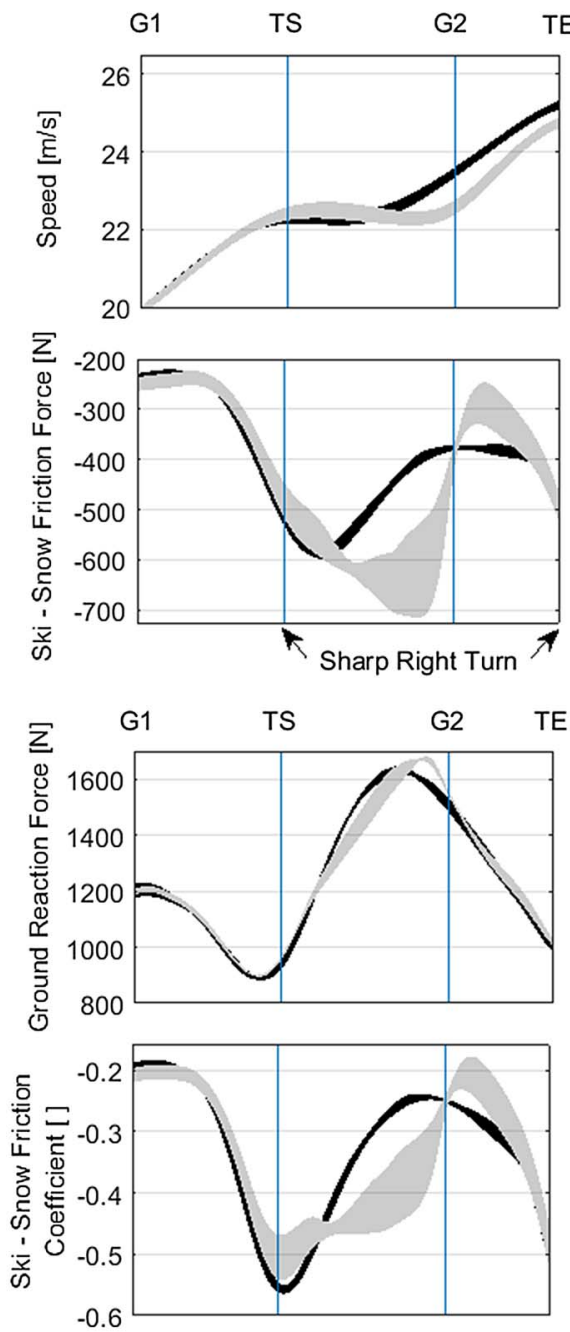

Skier B
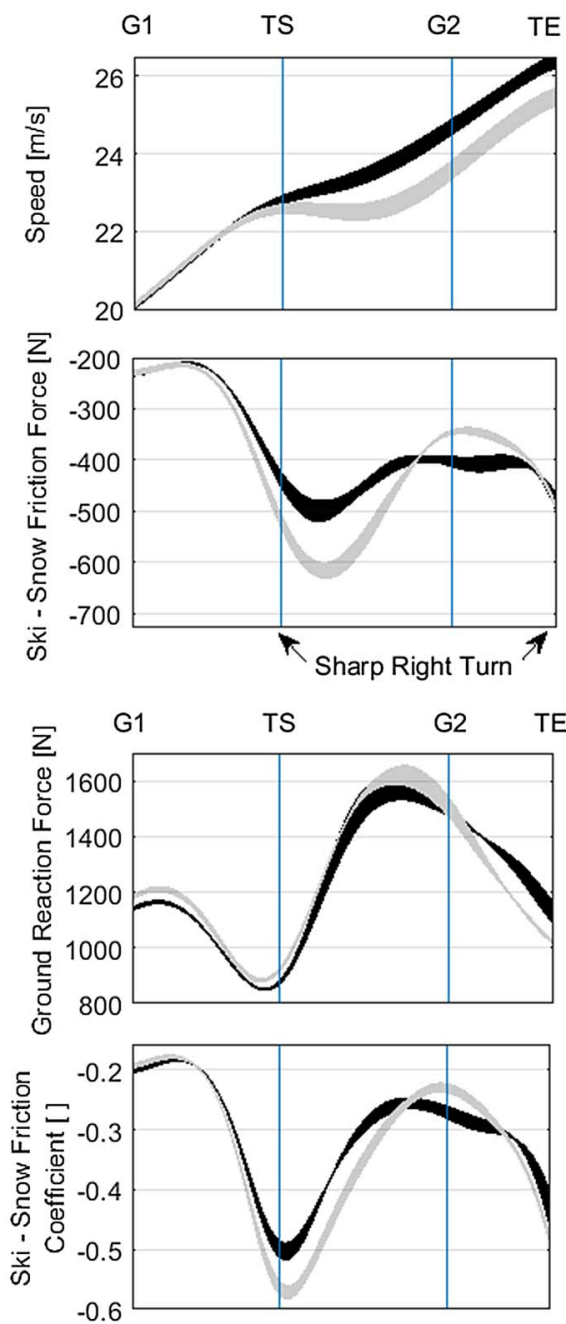

Local effects within the steep section

Within Section ${ }_{\text {STEEP }} \mathrm{SKI}_{\mathrm{WLH}}$ caused an average reduction in $\mathrm{E}_{\mathrm{KIN}}$ of $\sim 3 \%$ for both skiers. Locally, this reduction was sometimes even larger. A maximal reduction in $\mathrm{E}_{\mathrm{KIN}}(\sim-7.0 \%)$ was found during the sharp right turn at gate 2 for skier B. Within this specific subsection, the terrain was the steepest and turn radius was the smallest across the entire course. These findings illustrate the extent of the equipment-induced $\mathrm{E}_{\mathrm{KIN}}$ reduction can-locallyreach quite substantial magnitudes that are comparable to the ones achieved by course setting interventions. ${ }^{5614}$

For skier $\mathrm{B}$, the local reduction in $\mathrm{E}_{\mathrm{KIN}}$ during the sharp right turn at gate 2 was explained with a significant correlation between speed reduction and $\mathrm{F}_{\mathrm{F}}$ indicating that the loss in speed was mainly a result of higher ski-snow friction. An additional postanalysis from gate 1 to turn end after gate 2 found no difference in the CoM trajectories and turn radii as long as the skiers were turning (turn radius smaller than $125 \mathrm{~m}$ ), neither between $S K I_{W L H}$ and $\mathrm{SKI}_{\mathrm{REF}}$ within the same skier, nor between the skiers. Hence, it is reasonable that the differences in the skier's response to the equipment intervention at gate 2 are most likely not a result of different trajectories, but rather due to differences in the ski-snow interaction.

Explanation of the observed local effects in $\mathrm{F}_{\mathrm{F}}$ The analysis of how the observed effects in $F_{F}$ can be explained by variables related to the ski-snow interaction revealed that the differences in $\operatorname{Coeff}_{\mathrm{F}}$ contributed to a greater extent to the differences in $F_{\mathrm{F}}$, than $\mathrm{F}_{\mathrm{GRF}}$. Hence, even the most extreme ski prototype $\left(\mathrm{SKI}_{\mathrm{WLH}}\right)$ might not change the skier's movement patterns such that $\mathrm{F}_{\mathrm{GRF}}$ is substantially affected, but changes how the skis interact with the snow. For skier $B$ the increase in $\operatorname{Coeff}_{F}$ and, therefore, in $F_{F}$ seem to start early during the initiation phase of the turn (figure 4), and might be explained by an increased skidding prior to gate passage, as already observed for slalom skiing. ${ }^{20}$ For skier A the increase in Coeff $_{\mathrm{F}}$ was delayed and had a different pattern (figure 4).

\section{Ski geometry and standing height in the context of injury prevention}

High speed and, therefore, high $\mathrm{E}_{\mathrm{KIN}}$ have several aspects that might influence the risk of severe traumatic injuries in super-G and $\mathrm{DH}$.

First, in fall or crash situations, speed is a crucial factor, since the energy that is dissipated by forces during the impact increases with speed by the power of 2 . In this context, the observed equipment-induced reduction in $\mathrm{E}_{\mathrm{KIN}} /$ speed would theoretically lead to the same per cent wise reduction in the impulse (force over time) that acts in impact situations. Restated, a 3-7\% local reduction in $\mathrm{E}_{\mathrm{KIN}}$ would result in a reduction of the impact forces by $3-7 \%$ if the impact process time is held constant. However, it has to be pointed out that 
such a preventative gain can only be achieved when skiing on the most extreme ski prototype (ie, varying in width, standing height and length) and probably only within steep terrain, particularly if course setting causes small turn radii.

Second, anticipation and adaptation time within demanding course sections decrease with increasing $\mathrm{E}_{\mathrm{KIN}} /$ speed, which plausibly results in a higher risk for technical and tactical mistakes. ${ }^{3}$ Thus, a reduction in speed would give athletes more time to prepare for difficult course sections (eg, jumps, rough terrain transitions or turns) and make appropriate technical and/ or tactical decisions. However, the observed reduction in speed in this study would only lead to marginal changes in preparation and adaption time. Given that an athlete skis with the average speed of Section STEEP $(26.4 \mathrm{~m} / \mathrm{s})$ and oversees the upcoming course $20 \mathrm{~m}$ at a time, the observed equipment-induced reduction in speed would increase adaptation time by only $1 / 100-3$ / $100 \mathrm{~s}$. Hence, the preventative gain regarding this aspect is limited.

Third, increased $\mathrm{E}_{\mathrm{KIN}} /$ speed is known to increase jump distance and airtime and might result in severe consequences in case the skier makes mistakes at the take-off. ${ }^{3} \quad 4 \quad 21 \quad 22$ Concerning this aspect, the current study findings indicate that only if a jump is located directly within or after a steep section skis modified in length, width and standing height would markedly reduce $\mathrm{E}_{\mathrm{KIN}} /$ speed. In these situations, a $\sim 3 \%$ reduction in $\mathrm{E}_{\mathrm{KIN}} /$ speed would reduce jump distance and air time by $\sim 0.5 \mathrm{~m}$ and $\sim 2 / 100 \mathrm{~s}$, depending on the shape of the jump. ${ }^{3} 4$ Since many severe injuries are known to occur at jumps, ${ }^{23}$ this reduction-even though it is small-might serve as a certain preventative gain to protect the athlete's health.

Compared with the magnitude of the $\mathrm{E}_{\mathrm{KIN}}$ reduction, which might be achieved by course-related measures, ${ }^{5} 614$ the equipment-induced $3 \%$ reduction in $\mathrm{E}_{\mathrm{KIN}}$ in steep terrain and, therefore, the changes in preparation and adaption time to course features and the changes in jump distance and airtime seem to be rather small. However, by a smart combination with course-related and terrain-related measures, these small effects might become more relevant. Future studies should assess combined preventative measures including equipment and course setting modifications and investigate their effect on $\mathrm{E}_{\mathrm{KIN}} /$ speed. Knowing that only the most extreme equipment modification showed a preventative effect with respect to $\mathrm{E}_{\mathrm{KIN}}$, and considering that the athletes reported a delayed reaction in general and reduced rebound in the second part of the turn for $\mathrm{SKI}_{\mathrm{WLH}}$ and $\mathrm{SKI}_{\mathrm{WH}}$, ski ability and external attractiveness of the sport have to be considered. Benefits and costs must be balanced from an implementation point of view.

\section{Methodological considerations}

Since the study suffers from the small sample size and the limited number of repetitions per ski, the findings need to be interpreted with caution. Nevertheless, at this early stage of knowledge on injury prevention measures in $\mathrm{DH}$ and super-G, the new technology applied to top-level athletes in the current study might provide insights in the general mechanisms of skisnow interaction and the effect of modified equipment in the context of injury prevention. Hence, this study might serve as guidance for future studies in a field where previously no scientific knowledge was available.

\section{CONCLUSION}

Recent studies suggested that measures to prevent injuries in super-G and $\mathrm{DH}$ should aim at reducing speed and $\mathrm{E}_{\mathrm{KIN}}$ at spots where skiers are likely to crash. This is the first scientific study assessing equipment-related measures to reduce speed and $\mathrm{E}_{\mathrm{KIN}}$ in $\mathrm{DH}$. The study revealed that a simultaneous decrease in ski width and standing height and an increase in ski length reduces $\mathrm{E}_{\mathrm{KIN}}$ by $3 \%$, but within steep terrain only. Locally, even larger $\mathrm{E}_{\mathrm{KIN}}$ reductions of up to $7 \%$ were observed. This indicates that an equipment-induced reduction of $\mathrm{E}_{\mathrm{KIN}} / \mathrm{speed}$ is feasible and can be considered an efficient way to increase the athlete's safety in steep terrain. However, it must be stated that the preventative gain from modified DH skis is limited compared with other external preventative measures, such as course setting. Therefore, effective prevention strategies in $\mathrm{DH}$ should involve several different preventative measures that aim to radically slow down skiers at locations where crashes are likely to occur.

\section{What are the findings?}

- This study investigates for the first time the influence of ski equipment-related preventative measures (ski, width, standing height, ski length) on the risk factors kinetic energy and speed in downhill (DH).

- It adds more detailed insights into how ski geometry and standing height influence kinetic energy within an entire $\mathrm{DH}$ course.

\section{How might it impact on clinical practice in the future?}

- In steep terrain, longer skis with decreased width and standing height reduce average kinetic energy by $\sim 3 \%$. Locally, the magnitudes of energy reduction were even larger (up to $\sim 7 \%$ ).

- Speed and kinetic energy of the skier determine to a large extent the impact forces during fall and crash situations. Therefore, the observed equipment-induced reduction in kinetic energy can be considered an effective way to improve the athletes' safety, although compared with other external interventions, the preventative gain of modified $\mathrm{DH}$ skis is rather small.

Contributors JK, JS and EM conceptualised and coordinated the study and its design. JK and MG conducted the data collection. MG conducted the data processing and parameter calculation. MG and JS analysed the data. All authors contributed to the intellectual content, writing of the manuscript and approved its content

Funding This study was financially supported by the International Ski Federation (FIS) Injury Surveillance System (ISS) and the St Moritz Health and Innovation Foundation.

Competing interests None declared.

Ethics approval This study was approved by the Ethics Committee of the Department of Sport Science and Kinesiology at the University of Salzburg.

Provenance and peer review Not commissioned; externally peer reviewed.

Open Access This is an Open Access article distributed in accordance with the Creative Commons Attribution Non Commercial (CC BY-NC 4.0) license, which permits others to distribute, remix, adapt, build upon this work non-commercially, and license their derivative works on different terms, provided the original work is properly cited and the use is non-commercial. See: http://creativecommons.org/ licenses/by-nc/4.0/ 


\section{REFERENCES}

1 Florenes TW, Bere T, Nordsletten L, et al. Injuries among male and female World Cup alpine skiers. Br J Sports Med 2009;43:973-8.

2 Bere T, Florenes TW, Nordsletten L, et al. Sex differences in the risk of injury in World Cup alpine skiers: a 6-year cohort study. Br J Sports Med 2014; 48:36-40.

3 Gilgien M, Spörri J, Kröll J, et al. Mechanics of turning and jumping and skier speed are associated with injury risk in men's world cup alpine skiing: a comparison between the competition disciplines. Br J Sports Med 2014; 48:742-7.

4 Schindelwig K, Reichl W, Kaps P, et al. Safety assessment of jumps in ski racing. Scand J Med Sci Sports 2014;25:797-805.

5 Gilgien M, Crivelli P, Spörri J, et al. Characterization of course and terrain and their effect on skier speed in World Cup alpine ski racing. PLOS ONE 2015;10:e0118119.

6 Gilgien M, Crivelli P, Sporri J, et al. Correction: characterization of course and terrain and their effect on skier speed in world cup alpine ski racing. PLOS ONE 2015; 10:e0128899.

7 Spörri J, Kröll J, Amesberger G, et al. Perceived key injury risk factors in world cup alpine ski racing-an explorative qualitative study with expert stakeholders. $\mathrm{Br} \mathrm{J}$ Sports Med 2012;46:1059-64.

8 Federolf $\mathrm{P}$, Scheiber $\mathrm{P}$, Rauscher $\mathrm{E}$, et al. Impact of skier actions on the gliding times in alpine skiing. Scand J Med Sci Sports 2008;18:790-7.

9 Schiestl M, Kaps P, Mossner M, et al. Calculation of friction and reaction forces during an Alpine World Cup Downhill Race. In: Moritz E, Haake S, eds. The engineering of sport 6. New York: Springer, 2006:269-74.

10 Barelle C, Ruby A, Tavernier M. Experimental model of the aerodynamic drag coefficient in alpine skiing. J Appl Biomech 2004;20:167-76.

11 FIS. Specification for competition equipment and commercial markings. Edition 2011/2012 ed. Oberhofen, Switzerland: Self-publisher, 2011.

12 Gilgien M, Sporri J, Chardonnens J, et al. Determination of the centre of mass kinematics in alpine skiing using differential global navigation satellite systems. J Sports Sci 2015;33:960-9.
13 Gilgien M, Spörri J, Limpach $\mathrm{P}$, et al. The effect of different global navigation satellite system methods on positioning accuracy in elite alpine skiing. Sensors (Basel) 2014;14:18433-53.

14 Spörri J, Kröll J, Schwameder H, et al. Course setting and selected biomechanical variables related to injury risk in alpine ski racing: an explorative case study. Br J Sports Med 2012;46:1072-7.

15 Spörri J, Kröll J, Schwameder $H$, et al. Turn characteristics of a top world class athlete in giant slalom - a case study assessing current performance prediction concepts. Int J Sport Sci Coach 2012;7:647-59.

16 Gilgien M. Characterisation of skiers' mechanics, course setting and terrain geomorphology in World Cup Alpine Skiing using Global Navigation Satellite Systems: injury risk, performance and methodological aspects [Dissertation]. Norwegian School of Sport Sciences Oslo, 2014. ISBN: 978-82-502-0500-0.

17 Gilgien M, Spörri J, Chardonnens J, et al. Determination of external forces in alpine skiing using a differential global navigation satellite system. Sensors (Basel) 2013;13:9821-35.

18 Supej M, Hebert-Losier K, Holmberg HC. Impact of the steepness of the slope on the biomechanics of world cup slalom skiers. Int I Sports Physiol Perform 2015; 10:361-8

19 Supej M. Differential specific mechanical energy as a quality parameter in racing alpine skiing. J Appl Biomech 2008;24:121-9.

20 Reid R. A kinematic and kinetic study of alpine skiing technique in Slalom. [Dissertation]. Norwegian School of Sport Sciences Oslo, 2010. ISBN: 978-82-502-0440-9.

21 Heinrich D, van den Bogert AJ, Nachbauer W. Relationship between jump landing kinematics and peak ACL force during a jump in downhill skiing: a simulation study. Scand J Med Sci Sports 2014;24:e180-7.

22 Gerritsen KGM, Nachbauer W, van den Bogert AJ. Computer simulation of landing movement in downhill skiing: anterior cruciate ligament injuries. J Biomech 1996;29:845-54

23 Bere T, Florenes TW, Krosshaug T, et al. A systematic video analysis of 69 injury cases in World Cup alpine skiing. Scand J Med Sci Sports 2014;24:667-77. 